\title{
Influence of sagittal balance and physical ability associated with exercise on quality of life in middle-aged and elderly people
}

\author{
Shiro Imagama $\cdot$ Yukiharu Hasegawa • \\ Yukihiro Matsuyama • Yoshihito Sakai • Zenya Ito • \\ Nobuyuki Hamajima $\cdot$ Naoki Ishiguro
}

Received: 29 December 2010 / Accepted: 18 January 2011 /Published online: 11 February 2011

(C) International Osteoporosis Foundation and National Osteoporosis Foundation 2011

\begin{abstract}
Summary We examined 304 persons (135 males and 169 females) who underwent a basic health checkup to evaluate the relationship of quality of life (QOL) with osteoporosis, spinal sagittal balance, spinal mobility, muscle strength, and physical ability, including daily exercise. QOL of middle-aged
\end{abstract}

\footnotetext{
S. Imagama $(\bowtie) \cdot Y$. Hasegawa $\cdot N$. Ishiguro

Department of Orthopaedic Surgery,

Nagoya University Graduate School of Medicine,

65 Tsurumai-cho, Showa-ku,

Nagoya 466-8550 Aichi, Japan

e-mail: imagama@med.nagoya-u.ac.jp

\section{Y. Matsuyama}

Department of Orthopaedic Surgery,

Hamamatsu University School of Medicine,

1-20-1, Handayama, Higashi-ku,

Hamamatsu 431-3192 Shizuoka, Japan

Y. Sakai

Department of Orthopaedic Surgery,

National Center for Geriatrics and Gerontology,

Gengo 35, Morioka-cho,

Obu 474-8511 Aichi, Japan

Z. Ito

Department of Orthopaedic Surgery,

Toyohashi Municipal Hospital,

50, Hachikennishi, Aotake-cho,

Toyohashi 441-8570 Aichi, Japan

\section{N. Hamajima}

Preventive Medicine/Biostatics and Medical Decision Making, Nagoya University Graduate School of Medicine,

Nagoya, Japan
}

and elderly subjects was strongly related to sagittal balance and physical ability.

Introduction Spinal kyphosis with compression fracture and osteoporosis decrease QOL and increase mortality. However, it is unclear if kyphosis, spinal sagittal balance, muscle strength, and physical ability influence QOL.

Purpose The goal of the study was to evaluate the relationship of QOL with osteoporosis, spinal sagittal balance, spinal mobility, back muscle strength, and physical ability, including daily exercise, in middle-aged and elderly people.

Methods The subjects were 304 persons (135 males and 169 females) who underwent a basic health checkup. Lumbar lateral radiograph findings, sagittal balance and spinal mobility determined with SpinalMouse ${ }^{\circledR}$, grip, back muscle strength, and 10-m gait time were evaluated.

Results SF-36 physical component summary (PCS) scores showed a significant negative correlation with age $(r=-0.375)$, spinal inclination angle $(r=-0.322)$, and $10-\mathrm{m}$ gait time $(r=$ -0.470 ), and a significant positive correlation with percent of the young adult mean of bone mineral density $(r=0.223)$, lumbar lordosis angle $(r=0.184)$, thoracic spinal range of motion (ROM; $r=0.136)$, lumbar spinal ROM $(r=0.130)$, grip strength $(r=0.211)$, and back muscle strength $(r=0.301)$. In multiple regression analysis, age $(r=-0.372, p<0.0005)$, spinal inclination angle $(r=-0.336, p<0.05)$ and $10-\mathrm{m}$ gait time $(r=-2.898, p<0.0001)$ were significantly associated with SF-36 PCS $\left(\mathrm{R}^{2}=0.288\right)$. In the exercise group, $\mathrm{SF}-36$ PCS scores were significantly better $(p<0.05)$ due to good spinal balance, thoracic spinal ROM, back muscle strength, and gait speed. 
Conclusions QOL of middle-aged and elderly subjects was related to sagittal balance and physical ability. Thus, exercises for spine, muscle, and physical ability may improve QOL in middle-aged and elderly people.

Keywords Quality of life - Sagittal balance . Physical ability · Back muscle strength · Daily exercise . Middle-aged and elderly people

\section{Introduction}

The recent increase in the elderly population is likely to increase medical and nursing costs if many elderly people have difficulty in maintaining independence in their activities of daily living (ADL). Therefore, independence and improvement of the quality of life (QOL) of the elderly is needed in an aging society. Spinal compression fracture with osteoporosis is a common factor that decreases QOL $[1,2]$. Furthermore, Kado et al. recently found that hyperkyphosis predicts an increased risk of mortality in older women with vertebral fractures, independent of underlying spinal osteoporosis and the extent and severity of vertebral fractures [3]. Spinal kyphosis and abnormal slouch posture may also be associated with adverse health outcomes such as abdominal compression and impaired pulmonary function [4]. However, kyphotic spine has not been associated with spinal compression fractures in elderly people, but with postural changes [5], degenerative disc disease [6], and muscle weakness [7].

This background indicates a need to clarify the spinal factors associated with QOL and reduced mortality in elderly people. Several reports have shown that QOL of postmenopausal women is associated with lumbar spinal mobility and back muscle strength [8] and with back muscle exercise [9]. Our previous study showed that back muscle strength and spinal mobility are also important predictors of QOL in middle-aged and elderly males [10]. However, few studies have examined the relationship of spinal factors and muscle strength with QOL in males and females. Therefore, the objective of this study was to evaluate osteoporosis, spinal sagittal balance, spinal mobility, back muscle strength, and physical ability, including daily exercise, in middle-aged and elderly males and females, and to determine the relationship of these factors with QOL.

\section{Materials and methods}

The subjects were healthy volunteers who attended a basic health checkup supported by a local government in 2008 . This checkup has been held in the town of Yakumo in Hokkaido, Japan annually for 27 years and is well known among the local people, many of whom attend every year. The current study was performed in 304 subjects (135 males and 169 females) who received examinations with SpinalMouse ${ }^{\circledR}$ (Idiag, Volkerswill, Switzerland) for sagittal balance and spinal mobility and underwent lumbar radiography. The average age of these subjects was 66.7 years old (range, 50-88). Eight subjects were excluded from the study: three due to a history of spinal surgery, three with a history of spinal compression fracture, and two who did not agree to participate in the study. None of the subjects had rheumatoid arthritis or were receiving hemodialysis. SpinalMouse ${ }^{\circledR}$ data, lumbar lateral standing radiographs, grip strength, back muscle strength, 10-m gait time, body mass index (BMI), percent of the young adult mean (\% YAM) of bone mineral density (BMD), daily exercise habits, and QOL were examined as described below. Diagnosis of osteoporosis was based on criteria proposed by the Japanese Society for Bone and Mineral Research [11], and was defined as \%YAM $<70 \%$ in the calcaneus. The study was approved by the Committee on Ethics in Human Research of Nagoya University.

\section{Evaluation using SpinalMouse ${ }^{\circledR}$}

Spinal range of motion (ROM) and spinal angle were measured using SpinalMouse ${ }^{\circledR}$, which is an electronic computer-aided device that measures sagittal spinal ROM and intersegmental angles non-invasively using the so-called surface technique. Intraclass coefficients of $0.92-0.95$ have been determined for curvature measurement with SpinalMouse ${ }^{\circledR}$ [12]. In the current study, evaluation of the SpinalMouse ${ }^{\circledR}$ data showed a significant correlation with lumbar radiographic findings for the lumbar lordosis angle $(r=0.775 ; p<0.0001)$ and sacral inclination angle $(r=0.652 ; p<0.0001)$. This confirmed the reliability of the SpinalMouse ${ }^{\circledR}$ measurements of these angles and the data were then used for further analysis. This part of the health checkup is performed every year, using an approach described in a previous study [10]. The thoracic kyphosis angle, lumbar lordosis angle, sacral inclination angle, thoracic ROM, lumbar ROM, total spinal ROM, and spinal inclination angle were measured. Each angle was measured three times in a neutral standing position, maximum bending position, and maximum extension position, and average data were used. A greater spinal inclination angle reflects a posture that is bend forward, which gives poor sagittal balance. The thoracic kyphosis and lumbar lordosis angles are shown as positive values in this study.

Back muscle strength, grip strength, and 10-m gait time

Back muscle strength was determined from the maximal isometric strength of the trunk muscles in a standing posture with $30^{\circ}$ lumbar flexion using a digital back muscle 
strength meter (T.K.K.5402, Takei Co., Japan) [10]. Grip strength was tested with both hands in a standing position and averaged. The average force from two trials was recorded. The maximum strength in each trial was measured and these values showed high reproducibility $(r=0.990 ; p<0.0001)$. The $10-\mathrm{m}$ gait time was evaluated as a reflection of the physical ability of the subjects. This parameter was measured by a therapist who evaluated the maximum speed of the subjects without running. All subjects were assessed by one examiner who was blinded to the results of other evaluations.

\section{Interview}

Physical characteristics were determined by experienced interviewers at the time of the Comprehensive Health Examination Program to obtain information on gender, age, BMI, QOL, weekly exercise, and history of spine surgery. The SF-36 (Japanese version 2.0) was used for evaluation of QOL [13]. Support was provided so that the subjects could answer all questions by themselves. The eight scales and two summary measures of the SF-36, the physical component summary (PCS) and the mental component summary (MCS) were evaluated and their correlation with other factors was examined. For weekly exercise, information was obtained on the type of exercise, frequency per week, exercise time, and extent of exercise. The subjects were divided into an exercise group $(\operatorname{Ex}(+)$ group) comprising those with at least mild exercise (such as walking or a physical hobby) of over $2 \mathrm{~h}$ per week and without shortness of breath.

\section{Statistical analysis}

All data are shown as means \pm standard deviation (SD). Correlations between variables were analyzed using Pearson correlation coefficient analysis and simple regression analysis. Multiple regression analyses were conducted to determine which variables best correlated with balance. An unpaired $t$ test was used to evaluate differences between the groups of subjects with or without an exercise habit. Probability values of less than 0.05 were considered to be statistically significant.

\section{Results}

The mean values of measured variables in the subjects are listed in Table 1 and correlations between variables are shown in Table 2. Age had a significant correlation with most factors, except for BMI and SF-36 MCS. BMI was correlated positively with the spinal inclination angle and $10-\mathrm{m}$ gait time. \%YAM showed significant negative
Table 1 Background data for the subjects

\begin{tabular}{|c|c|c|c|}
\hline Variables & Mean & SD & Range \\
\hline Age (years) & 66.7 & 8.9 & $50-88$ \\
\hline BMI $\left(\mathrm{kg} / \mathrm{m}^{2}\right)$ & 23.8 & 3.2 & $15.4-35.9$ \\
\hline$\%$ YAM & 76.9 & 17.6 & $38-181$ \\
\hline Thoracic kyphosis angle $\left(^{\circ}\right)$ & 40.8 & 9.1 & $13-68$ \\
\hline Lumbar lordosis angle $\left({ }^{\circ}\right)$ & 20.3 & 10.4 & $19-46$ \\
\hline Sacral inclination angle $\left(^{\circ}\right)$ & 9.0 & 7.5 & -15 to 30 \\
\hline Spine inclination angle $\left(^{\circ}\right)$ & 0.97 & 4.4 & -14 to 21 \\
\hline Thoracic spinal ROM $\left(^{\circ}\right)$ & 18.6 & 15.0 & $0-71$ \\
\hline Lumbar spinal ROM $\left(^{\circ}\right)$ & 50.0 & 17.3 & $2-97$ \\
\hline Grip strength (kg) & 29.8 & 8.6 & $2.5-55.5$ \\
\hline Back muscle strength (kg) & 74.1 & 30.1 & $5-178.5$ \\
\hline 10-m gait time & 5.5 & 1.2 & $2.9-12.3$ \\
\hline \multicolumn{4}{|l|}{ SF36 } \\
\hline $\mathrm{PF}$ & 84.3 & 16.0 & $15-100$ \\
\hline $\mathrm{RP}$ & 85.8 & 20.5 & $0-100$ \\
\hline $\mathrm{BP}$ & 73.2 & 23.2 & $0-100$ \\
\hline GH & 61.4 & 18.3 & $5-100$ \\
\hline VT & 65.3 & 19.9 & $6.3-100$ \\
\hline $\mathrm{SF}$ & 89.2 & 17.1 & $25-100$ \\
\hline $\mathrm{RE}$ & 87.1 & 21.3 & $0-100$ \\
\hline MH & 75.2 & 18.0 & $30-100$ \\
\hline PCS & 47.5 & 11.6 & $0.54-65.2$ \\
\hline MCS & 52.1 & 8.7 & $21.8-74.4$ \\
\hline
\end{tabular}

$B M I$ body mass index, \% YAM percent of young adult mean of bone mineral density, $R O M$ range of motion, $P F$ physical functioning, $R P$ role-physical, $B P$ bodily pain, $G H$ general health perception, $V T$ vitality, $S F$ social functioning, $R E$ role-emotional, $M H$ mental health, $P C S$ physical component summary, $M C S$ mental component summary

correlations with sacral inclination angle, spinal inclination angle, and $10-\mathrm{m}$ gait time, and positive correlations with lumbar ROM, grip strength, back muscle strength, SF-36 PCS, and SF-36 MCS. Data for spinal factors had significant correlations with many other factors, with spinal inclination angle showing negative correlations with \%YAM, lumbar lordosis, back muscle strength, and SF-36 PCS, and positive correlations with age, BMI, lumbar ROM and 10-m gait time, but no correlations with thoracic factors. A significant correlation of back muscle strength was found with all items except for BMI and lumbar lordosis angle. A significant correlation of 10 -m gait time was found with all items except for sacral inclination angle.

Regarding QOL, SF-36 PCS showed a significant negative correlation with age, spinal inclination angle, and 10-m gait time, and a significant positive correlation with \% YAM, lumbar lordosis angle, thoracic and lumbar ROM, grip strength, and back muscle strength. SF-36 MCS showed a significant positive correlation with \%YAM, grip 


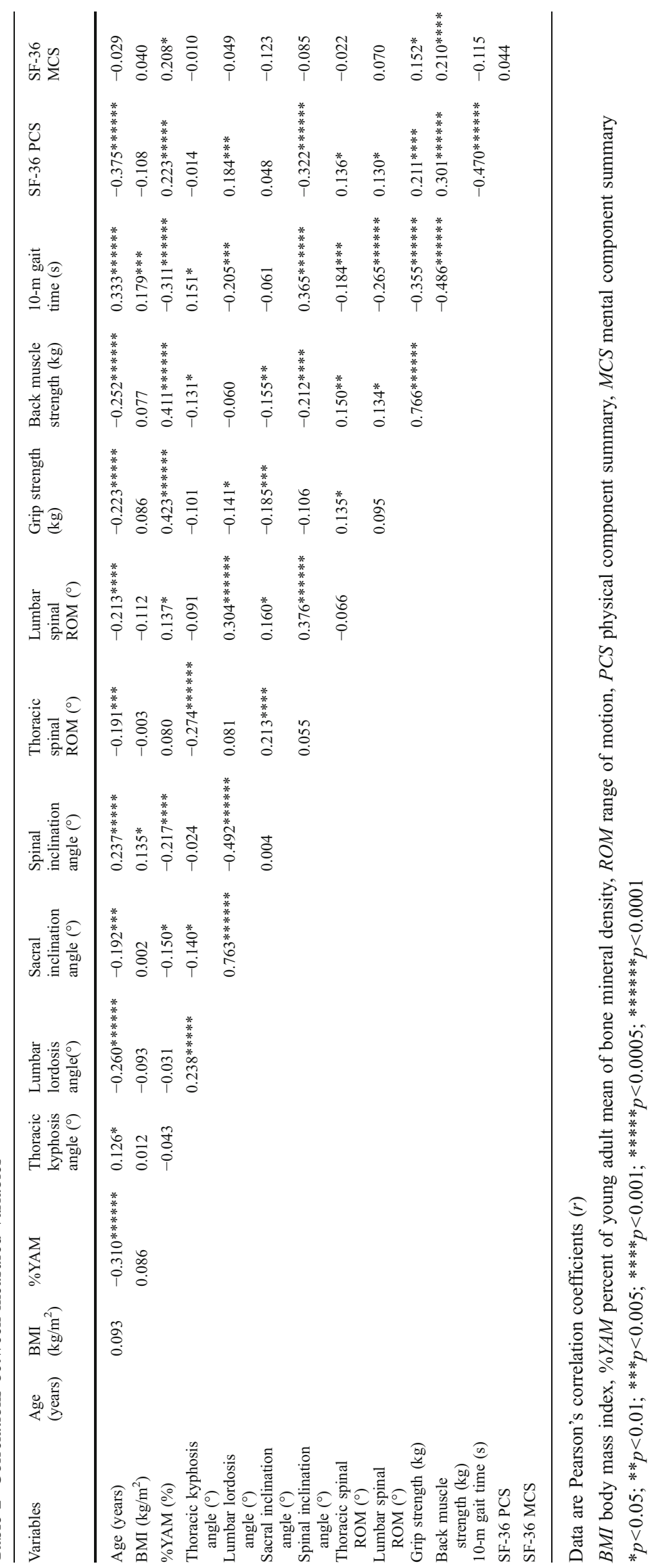


strength, and back muscle strength. Correlations between each SF-36 scale and the measured variables were also evaluated (Table 3). Physical functioning, which largely affects SF-36 PCS, showed a significant correlation with all factors except for thoracic factors and sacral inclination angle. This tendency was also found for role-physical, and role-emotional. Among spinal factors, spinal inclination angle had a significant correlation with five of the eight SF36 scales. Among all the factors, only \%YAM and back muscle strength showed a significant positive correlation with all SF-36 scales, but grip strength and 10-m gait time also had a correlation with most scales.

Based on these results, age, \%YAM, lumbar lordosis angle, spinal inclination angle, thoracic and lumbar spinal ROM, grip strength, back muscle strength, and 10-m gait time were selected as independent variables in a multiple regression model for SF-36 PCS. In this model, age, spinal inclination angle and 10-m gait time were significant contributors to the SF-36 PCS score (Table 4). No other variables were significantly associated with SF-36 PCS. The coefficient of determination $\left(R^{2}\right)$ in the multiple regression model was 0.288 , indicating that $28.8 \%$ of the variability in the SF-36 PCS score was explained by all the variables.

A comparison of the subjects with and without exercise habits is shown in Table 5, interestingly, the subjects in the $\operatorname{Ex}(+)$ group $(n=122,40.1 \%)$ were significantly older than those in the $\operatorname{Ex}(-)$ group. Spinal inclination angle and $10-\mathrm{m}$ gait time were significantly lower, and thoracic spinal ROM and SF-36 PCS score were significantly higher in the $\operatorname{Ex}(+)$
Table 4 Multiple regression analysis of factors associated with SF-36 PCS scores

\begin{tabular}{lcc}
\hline Variables & Coefficient $(r)$ & Significance $(p)$ \\
\hline Age (years) & -0.372 & $0.0004^{\mathrm{a}}$ \\
\%YAM & 0.006 & 0.888 \\
Lumbar lordosis angle $\left(^{\circ}\right)$ & 0.017 & 0.825 \\
Spinal inclination angle $\left(^{\circ}\right)$ & -0.336 & $0.048^{\mathrm{a}}$ \\
Thoracic spinal ROM $\left(^{\circ}\right)$ & 0.018 & 0.682 \\
Lumbar spinal ROM $\left(^{\circ}\right)$ & -0.040 & 0.321 \\
Grip strength $(\mathrm{kg})$ & -0.097 & 0.397 \\
Back muscle strength $(\mathrm{kg})$ & -0.050 & 0.149 \\
10-m gait time $(\mathrm{s})$ & -2.898 & $<0.0001^{\mathrm{a}}$ \\
\hline
\end{tabular}

PCS physical component summary, \%YAM percent of young adult mean of bone mineral density, $R O M$ range of motion

${ }^{\text {a }}$ Significant difference

group. Back muscle strength also showed a tendency for an association with exercise, but the difference between the two groups was not significant.

Osteoporosis was present in 109 subjects $(35.9 \%)$. A higher percentage of females had osteoporosis $(p<0.005)$, but QOL and exercise habits did not differ between subjects with and without osteoporosis. Muscle strength was significantly smaller and $10-\mathrm{m}$ gait time was significantly longer in females than in males, but there were no significant gender differences in thoracic kyphosis, spinal inclination angle, and QOL.

Table 3 Correlations between SF-36 scales and other variables

\begin{tabular}{|c|c|c|c|c|c|c|c|c|}
\hline Variables & $\mathrm{PF}$ & $\mathrm{RF}$ & $\mathrm{BP}$ & GH & VT & SF & $\mathrm{RE}$ & MH \\
\hline Age (years) & $-0.392 * * * * * *$ & $-0.281 * * * * * *$ & $-0.139^{*}$ & $-0.130 *$ & $-0.191 * * *$ & -0.034 & $-0.294 * * * * * *$ & -0.077 \\
\hline BMI $\left(\mathrm{kg} / \mathrm{m}^{2}\right)$ & $-0.137^{*}$ & -0.058 & -0.004 & 0.001 & -0.075 & 0.073 & -0.073 & 0.010 \\
\hline$\%$ YAM & $0.277 * * * * * *$ & $0.155^{*}$ & $0.184 * * *$ & $0.155^{*}$ & $0.317 * * * * * *$ & $0.132 *$ & $0.232 * * * * *$ & $0.179 * *$ \\
\hline $\begin{array}{l}\text { Thoracic kyphosis } \\
\text { angle }\left(^{\circ}\right)\end{array}$ & -0.075 & 0.018 & 0.026 & -0.034 & -0.018 & 0.020 & 0.017 & 0.013 \\
\hline $\begin{array}{l}\text { Lumbar lordosis } \\
\text { angle }\left(^{\circ}\right)\end{array}$ & $0.161^{*}$ & $0.152 *$ & -0.008 & 0.088 & 0.041 & 0.003 & $0.127^{*}$ & -0.013 \\
\hline $\begin{array}{l}\text { Sacral inclination } \\
\text { angle }\left({ }^{\circ}\right)\end{array}$ & 0.033 & 0.057 & -0.071 & 0.007 & -0.087 & -0.011 & 0.051 & -0.067 \\
\hline $\begin{array}{l}\text { Spinal inclination } \\
\text { angle }\left(^{\circ}\right)\end{array}$ & $-0.307 * * * * * *$ & $-0.192 * * *$ & -0.078 & $-0.135^{*}$ & $-0.218^{* * * *}$ & -0.054 & $-0.165^{* *}$ & -0.065 \\
\hline Thoracic spinal ROM $\left(^{\circ}\right)$ & 0.081 & 0.055 & 0.051 & 0.116 & -0.043 & 0.033 & 0.067 & -0.046 \\
\hline Lumbar spinal ROM $\left(^{\circ}\right)$ & $0.171 * *$ & 0.066 & 0.087 & 0.086 & 0.123 & 0.056 & 0.055 & 0.067 \\
\hline Grip strength (kg) & $0.313 * * * * * *$ & $0.135^{*}$ & $0.182 * * *$ & 0.115 & $0.212 * * * *$ & $0.131 *$ & $0.138^{*}$ & $0.154 *$ \\
\hline $\begin{array}{l}\text { Back muscle strength } \\
(\mathrm{kg})\end{array}$ & $0.342 * * * * * *$ & $0.248 * * * * * *$ & $0.262 * * * * * *$ & $0.226 * * * * *$ & $0.296 * * * * * *$ & $0.162 *$ & $0.256 * * * * * *$ & $0.203 * * *$ \\
\hline 10-m gait time (s) & $-0.463 * * * * * *$ & $-0.353 * * * * * *$ & $-0.182 * * *$ & $-0.275 * * * * * *$ & $-0.295 * * * * * *$ & -0.104 & $-0.317 * * * * * *$ & $-0.161 *$ \\
\hline
\end{tabular}

Data are Pearson's correlation coefficients $(r)$

$B M I$ body mass index, \%YAM percent of young adult mean of bone mineral density, $R O M$ range of motion, $P F$ physical functioning, $R P$ rolephysical, $B P$ bodily pain, $G H$ general health perception, $V T$ vitality, $S F$ social functioning, $R E$ role-emotional, $M H$ mental health

${ }^{*} p<0.05 ; * * p<0.01 ; * * * p<0.005 ; * * * * p<0.001 ; * * * * p<0.0005 ; * * * * * * p<0.0001$ 
Table 5 Comparison of subjects with $(\operatorname{Ex}(+))$ and without $(\operatorname{Ex}(-))$ an exercise habit

Data are shown as the mean with the standard deviation in parentheses.

${ }^{\mathrm{a}}$ Significant difference

$B M I$ body mass index, \%YAM percent of young adult mean of bone mineral density, ROM range of motion, $P C S$ physical component summary, MCS mental component summary

\begin{tabular}{lccc}
\hline Variables & $\begin{array}{l}\text { Ex(+) group } \\
n=122\end{array}$ & $\begin{array}{l}\text { Ex }(-) \text { group } \\
n=182\end{array}$ & Significance $(p)$ \\
\hline Age (years) & $68.3(7.2)$ & $65.7(9.8)$ & $0.014^{\mathrm{a}}$ \\
BMI $\left(\mathrm{kg} / \mathrm{m}^{2}\right)$ & $23.6(3.3)$ & $23.8(3.0)$ & 0.740 \\
\%YAM & $77.4(16.5)$ & $76.6(18.4)$ & 0.681 \\
Thoracic kyphosis angle $\left(^{\circ}\right)$ & $41.6(8.4)$ & $40.3(9.6)$ & 0.221 \\
Lumbar lordosis angle $\left(^{\circ}\right)$ & $21.1(8.9)$ & $19.7(11.3)$ & 0.263 \\
Sacral inclination angle $\left(^{\circ}\right)$ & $9.0(7.0)$ & $9.1(7.8)$ & 0.968 \\
Spinal inclination angle $\left(^{\circ}\right)$ & $0.336(3.3)$ & $1.40(4.9)$ & $0.038^{\mathrm{a}}$ \\
Thoracic spinal ROM $\left(^{\circ}\right)$ & $20.1(14.9)$ & $16.3(14.9)$ & $0.027^{\mathrm{a}}$ \\
Lumbar spinal ROM $\left(^{\circ}\right)$ & $51.4(16.4)$ & $49.1(17.9)$ & 0.260 \\
Grip strength $(\mathrm{kg})$ & $30.6(8.3)$ & $29.3(8.8)$ & 0.191 \\
Back muscle strength $(\mathrm{kg})$ & $77.3(25.1)$ & $70.1(30.1)$ & 0.071 \\
10-m gait time (s) & $5.3(0.98)$ & $5.6(1.3)$ & $0.045^{\mathrm{a}}$ \\
SF-36 PCS & $49.6(10.1)$ & $45.9(12.4)$ & $0.011^{\mathrm{a}}$ \\
SF-36 MCS & $52.1(9.2)$ & $52.2(8.3)$ & 0.947 \\
\hline
\end{tabular}

\section{Discussion}

Maintenance of ADL and QOL in elderly people is important in an aging society. Spinal compression fractures and spinal deformity are factors that decrease ADL and QOL [14-20], and our previous study of 100 middle-aged and elderly males showed that sagittal balance, lumbar lordosis angle, spinal ROM, and back muscle strength may also be important factors related to QOL [10]. Miyakoshi et al. found that a decrease in spinal ROM had negative effects on QOL and that deterioration of back muscle strength was the most important factor decreasing spinal ROM in postmenopausal women with osteoporosis aged 50 years old or older, indicating that maintenance of back muscle strength and lumbar ROM are important for QOL [8]. Thus, spinal factors and muscle strength seem to be related to QOL in middle-aged and elderly people, but the details of this relationship have not been investigated. Thus, the current study is the first to evaluate the influence of spinal angles, spinal sagittal alignment, spinal ROM, and grip and back muscle strength, as well as gait speed and daily exercise, on QOL in both males and females.

Our results showed that sagittal balance, spinal ROM, lumbar lordosis, \%YAM, muscle strength, physical ability, and exercise are related to QOL in elderly persons. In multiple regression analysis of these factors, sagittal balance and physical ability (10-m gait time) were the most important contributors to QOL. Regarding sagittal balance, multiple vertebral fractures result in postural deformities that may cause functional impairment in $\mathrm{ADL}[19,21,22]$ and lead to reduction of QOL [23-28]. The subjects were healthy volunteers who participated in a health checkup, and subjects with a history of spinal compression fractures were excluded. Therefore, thoracic spine factors had no relationship with spinal inclination angle, and our results showed that poor sagittal balance without compression fractures or thoracic kyphosis (a so-called "slouch posture") influences QOL directly in elderly persons. In particular, the significant correlation of spinal balance with SF-36 PCS, but not with MCS, suggests that subjects with poor sagittal balance have physical difficulty with ADL because they tend to bend forward. This relationship requires further investigation, but poor sagittal alignment should be recognized as a predictor of poor QOL in elderly males and females, even in those without compression fracture or excessive thoracic kyphosis.

Physical ability reflected by the $10-\mathrm{m}$ gait time was another important contributor to QOL, and showed correlations with SF-36 PCS and MCS. The 10-m gait time had a significant correlation with all factors except for sacral inclination angle, and may be a good indicator of aging, muscle strength, and QOL, as well as physical activity, in elderly persons. Kyphosis has previously been associated with gait function in the elderly [19, 29]. Subjects with an exercise habit (including mild exercise) had significantly better sagittal alignment, thoracic spinal ROM, 10-m gait time, and SF-36 PCS, and a tendency for greater back muscle strength, compared with those with no exercise habit. The exercise group was also significantly older, which suggests that exercise has an important impact on these factors in elderly persons regardless of age. Hongo et al. showed that back muscle training resulted in a significant improvement of QOL in a randomized controlled study [9]. Thus, exercise in elderly persons may be important to maintain spinal balance, spinal motion, muscle strength, and physical ability, and improvement of these characteristics should result in maintenance of QOL. 
Several limitations of the study should be noted. Regarding the high prevalence of exercise, many of the subjects had jobs in agriculture or fishing, and may have had more interest in their health compared with other elderly persons. However, we were able to clarify the effect of exercise based on other factors. The subjects were also healthy volunteers with a low rate of osteoporosis, which might explain the absence of an association of osteoporosis with other factors. The definition of osteoporosis using BMD in the calcaneus might be a further limitation, but this approach is the only one available in a basic health checkup. Our results showed that \%YAM had a significant correlation with all eight scales, PCS, and MCS in SF-36, which indicates that osteoporosis was related to decreased QOL. Finally, we note that there is a current focus on studies on spinal compression fracture in females with osteoporosis in hospitals. Therefore conducting more studies that include evaluation of osteoporosis in both males and females in a community health checkup is also important.

In conclusion, the results of this study clarified the relationships of spinal alignment, spinal ROM, muscle strength, and physical ability with QOL in middle-aged and elderly people without compression fracture. We believe that these results are of importance for maintenance of QOL in the elderly, and we suggest that exercise should be encouraged in elderly people to promote spinal balance, muscle strength, physical ability, and QOL.

Acknowledgement The authors appreciate the staffs of the Comprehensive Health Care Program held in Yakumo, Hokkaido. We also thank Ms. Kae Shikii and Ms. Saho Horiuchi of Nagoya University for their assistance of data collection. This study was supported by The Japanese Ministry of Health, Labor, and Welfare with Grant-in Aid for Scientific Research (B)(2)(20390397).

Conflicts of interest statement The authors report no conflicts of interest and no disclosures.

\section{References}

1. Dhillon V, Hurst N, Hannan J, Nuki G (2005) Association of low general health status, measured prospectively by Euroqol EQ5D, with osteoporosis, independent of a history of prior fracture. Osteoporos Int 16:483-489

2. Pluijm SM, Tromp AM, Smit JH, Deeg DJ, Lips P (2000) Consequences of vertebral deformities in older men and women. $\mathrm{J}$ Bone Miner Res 15:1564-1572

3. Kado DM, Lui LY, Ensrud KE, Fink HA, Karlamangla AS, Cummings SR (2009) Hyperkyphosis predicts mortality independent of vertebral osteoporosis in older women. Ann Intern Med $150: 681-687$

4. Kado DM, Prenovost K, Crandall C (2007) Narrative review: hyperkyphosis in older persons. Ann Intern Med 147:330-338

5. Hinman MR (2004) Comparison of thoracic kyphosis and postural stiffness in younger and older women. Spine J 4:413-417
6. Schneider DL, von Muhlen D, Barrett-Connor E, Sartoris DJ (2004) Kyphosis does not equal vertebral fractures: the Rancho Bernardo study. J Rheumatol 31:747-752

7. Mika A, Unnithan VB, Mika P (2005) Differences in thoracic kyphosis and in back muscle strength in women with bone loss due to osteoporosis. Spine 30:241-246

8. Miyakoshi N, Hongo M, Maekawa S, Ishikawa Y, Shimada Y, Itoi E (2007) Back extensor strength and lumbar spinal mobility are predictors of quality of life in patients with postmenopausal osteoporosis. Osteoporos Int 18:1397-1403

9. Hongo M, Itoi E, Sinaki M, Miyakoshi N, Shimada Y, Maekawa S, Okada K, Mizutani Y (2007) Effect of low-intensity back exercise on quality of life and back extensor strength in patients with osteoporosis: a randomized controlled trial. Osteoporos Int 18:1389-1395

10. Imagama S, Matsuyama Y, Hasegawa Y, Sakai Y, Ito Z, Ishiguro N, Hamajima N (2011) Back muscle strength and spinal mobility are predictors of quality of life in middle-aged and elderly males. Eur Spine J (in press)

11. Orimo H, Hayashi Y, Fukunaga M et al (2001) Diagnostic criteria for primary osteoporosis: year 2000 revision. J Bone Miner Metab 19:331-337

12. Post RB, Leferink VJ (2004) Spinal mobility: sagittal range of motion measured with the SpinalMouse, a new non-invasive device. Arch Orthop Trauma Surg 124:187-192

13. Ware JE Jr (2000) SF-36 health survey update. Spine 25:3130-3139

14. Cortet B, Houvenagel E, Puisieux F, Roches E, Garnier P, Delcambre B (1999) Spinal curvatures and quality of life in women with vertebral fractures secondary to osteoporosis. Spine 24:1921-1925

15. Hirose D, Ishida K, Nagano Y, Takahashi T, Yamamoto H (2004) Posture of the trunk in the sagittal plane is associated with gait in community-dwelling elderly population. Clin Biomech (Bristol, Avon) 19:57-63

16. Kado DM, Huang MH, Barrett-Connor E, Greendale GA (2005) Hyperkyphotic posture and poor physical functional ability in older community-dwelling men and women: the Rancho Bernardo study. J Gerontol A Biol Sci Med Sci 60:633-637

17. Lombardi I Jr, Oliveira LM, Monteiro CR, Confessor YQ, Barros TL, Natour J (2004) Evaluation of physical capacity and quality of life in osteoporotic women. Osteoporos Int 15:80-85

18. Ryan PJ, Blake G, Herd R, Fogelman I (1994) A clinical profile of back pain and disability in patients with spinal osteoporosis. Bone 15:27-30

19. Ryan SD, Fried LP (1997) The impact of kyphosis on daily functioning. J Am Geriatr Soc 45:1479-1486

20. Sinaki M, Itoi E, Rogers JW, Bergstralh EJ, Wahner HW (1996) Correlation of back extensor strength with thoracic kyphosis and lumbar lordosis in estrogen-deficient women. Am J Phys Med Rehabil 75:370-374

21. Martin AR, Sornay-Rendu E, Chandler JM, Duboeuf F, Girman CJ, Delmas PD (2002) The impact of osteoporosis on quality-of-life: the OFELY cohort. Bone 31:32-36

22. Nevitt MC, Ettinger B, Black DM, Stone K, Jamal SA, Ensrud K, Segal M, Genant HK, Cummings SR (1998) The association of radiographically detected vertebral fractures with back pain and function: a prospective study. Ann Intern Med 128:793-800

23. Adachi JD, Ioannidis G, Olszynski WP et al (2002) The impact of incident vertebral and non-vertebral fractures on health related quality of life in postmenopausal women. BMC Musculoskelet Disord 3:11

24. Lips P, Cooper C, Agnusdei D et al (1999) Quality of life in patients with vertebral fractures: validation of the Quality of Life Questionnaire of the European Foundation for Osteoporosis (QUALEFFO). Working Party for Quality of Life of the European Foundation for Osteoporosis. Osteoporos Int 10:150-160 
25. Lips P, Cooper C, Agnusdei D et al (1997) Quality of life as outcome in the treatment of osteoporosis: the development of a questionnaire for quality of life by the European Foundation for Osteoporosis. Osteoporos Int 7:36-38

26. Miyakoshi N, Itoi E, Kobayashi M, Kodama H (2003) Impact of postural deformities and spinal mobility on quality of life in postmenopausal osteoporosis. Osteoporos Int 14:10071012

27. Oleksik A, Lips P, Dawson A, Minshall ME, Shen W, Cooper C, Kanis J (2000) Health-related quality of life in postmenopausal women with low BMD with or without prevalent vertebral fractures. J Bone Miner Res 15:1384-1392

28. Silverman SL, Minshall ME, Shen W, Harper KD, Xie S (2001) The relationship of health-related quality of life to prevalent and incident vertebral fractures in postmenopausal women with osteoporosis: results from the Multiple Outcomes of Raloxifene Evaluation Study. Arthritis Rheum 44:2611-2619

29. Huang C, Ross PD, Wasnich RD (1996) Vertebral fracture and other predictors of physical impairment and health care utilization. Arch Intern Med 156:2469-2475 